\title{
DISKONTNA MERA PRI UPORABI METOD, KI TEMELJIJO NA DISKONTIRANEM DENARNEM TOKU, ZA POTREBE ANALIZE NEPREMIČNINSKIH NALOŽB IN VREDNOTENJA NEPREMIČNIN
}

\author{
DISCOUNT RATE IN METHODS BASED ON DISCOUNTED CASH-FLOW FOR THE \\ PURPOSE OF REAL ESTATE INVESTMENT ANALYSIS AND VALUATION
}

\author{
Igor Pšunder, Andreja Cirman
}

UDK: 332.64:657.92

\section{IZVLEČEK}

Uporaba metod analize nepremičninskih in drugih naložb, ki temeljijo na diskontiranju denarnega toka, se je uveljavila šele v zadnjih nekaj desetletjih. Kljub relativno veliki razširjenosti metod, ki temeljijo na diskontiranju denarnega toka, projektni vodje po lastnem mnenju ne poznajo dovolj posebnosti metod, celo takšnih ne, ki bi lahko privedle do napačnih odlociitev (npr. navzkrižne indikacije metode neto sedanje vrednosti in notranje donosnosti). Ena ključnih pomanjkljivosti uporabe metod analize naložb, ki temeljijo na diskontiranju denarnega toka, pa je ne dovolj natančno določena diskontna mera oziroma mera kapitalizacije.

Metode, ki temeljijo na diskontiranju denarnega toka, niso namenjene zgolj analizi ekonomske upravičenosti projektov, temvečje na diskontiranem denarnem toku zasnovano tudi vrednotenje posebnih nepremičnin $v$ sistemu množičnega vrednotenja nepremičnin $v$ Sloveniji.

$V$ tem članku je obravnavan pomen diskontne mere $z$ a analizo in vrednotenje nepremicninskih projektov. $V$ teoretičnem delu so predstavljene zasnova metod, $k i$ temelijo na diskontiranem denarnem toku, sestava diskontne mere in mere kapitalizacije ter simulacija vpliva diskontne mere oziroma mere kapitalizacije na rezultate evalvacije in vrednotenja.

Empirični del sloni na anketi med pooblaščenimi ocenjevalci vrednosti nepremičnin pri nas. Anketa je bila izvedena v februarju in marcu 2011 med pooblaščenimi ocenjevalci vrednosti nepremičnin, $v$ njej je sodelovalo 32,9\% vseh pooblaščenih
Klasifikacija prispevka po COBISS-u: 1.02

\begin{abstract}
During the last few decades there has been an increase in the use of methods of real estate investment and other investment analyses based on discounted cash flow. Despite the relatively wide use of discounted cash flow methods, project managers believe their own knowledge of these methods is insufficient even to the extent where this could lead to incorrect decisions (e.g. conflicting indications of the net present value method and the internal rate of return method). One of major drawbacks in the use of investment analysis methods that are based on discounted cash flow is unsatisfactory precision in the determination of the discount or the capitalization rate.
\end{abstract}

Methods based on discounted cash flow are not only intended for project feasibility analysis; discounted cash flow serves as a basis for assessing special real estate within the mass real estate appraisal system in Slovenia.

The article studies the importance of the discount rate when analysing and assessing real estate projects. The theoretical part presents the basis of discounted cash flow methods and composition of the discount rate or capitalisation rate and presents a simulation of the impact of the discount rate and capitalisation rate on investment evaluation and assessment results.

The empirical part is based on a survey conducted among certified real estate appraisers in Slovenia. The survey was conducted in the second half of February and beginning of March 2011. The response rate was 32.9 percent, indicating that almost one-third of all certified appraisers in Slovenia participated. Survey 
ocenjevalcev vrednosti nepremičnin v Sloveniji. Odgovori so statistično obdelani, iz rezultatov pa so pridobljeni podatki za diskontno mero za različne vrste nepremičnin ter izračunane premije za tveganja ter premije za ohranitev kapitala pri različnih vrstah nepremičnin.

\section{KLJUČNE BESEDE}

diskontna mera, mera kapitalizacije, premija za tveganja, premija za ohranitev kapitala, neto sedanja vrednost, analiza nepremičninskih naložb data were statistically analysed and the results provide us with the discount rate and calculated risk premium and capital recovery premium for various type of real estate. A statistical analysis of the survey data provides insights into the risk premium and capital recovery premium used for real estate appraisal and investment purposes.

\section{KEY WORDS}

discount rate, capitalisation rate, risk premium, capital recovery premium, net present value, real estate investment analysis, special real estate appraisal

\section{UVOD}

Metode presoje nepremičninskih in drugih naložb, ki temeljijo na diskontiranju denarnega toka (angl. discounted cash flow methods - DCF), so se začele uveljavljati šele v zadnjih petdesetih letih. Raziskave kažejo, da se je v Združenih državah Amerike njihova uporaba v projektih, ki se nanašajo na uvajanje novih dejavnosti, povzpela z 41 \% v letu 1970 na 58 \% v letu 1975 in na 71 \% v letu 1980 (Klammer in Walker, 1984). Podobno rast pogostosti uporabe metod, ki temeljijo na diskontiranju denarnega toka, so ugotovili za Veliko Britanijo. Leta 1986 je v velikih podjetjih 84 \% naložbenih odločitev temeljilo na metodi neto sedanje vrednosti (angl. net present value - NPV) ali interne donosnosti oziroma notranje stopnje donosa (angl. internal rate of return - IRR) (Pike, 1988).

Raziskava, ki sta jo opravila Pšunder in Ferlan (2008) med projektnimi vodjami v 44 slovenskih podjetjih, kaže, da je uporaba metod, ki temeljijo na diskontiranju denarnega toka, odvisna od področja njihove izobrazbe. Le 50 \% projektnih vodij, ki imajo izobrazbo s področja gradbeništva, uporablja metodo neto sedanje vrednosti, 66,7 \% pa metodo interne donosnosti. Za primerjavo navedimo, da metodo neto sedanje vrednosti pri naložbenih odločitvah uporablja $70,6 \%$ projektih vodij z izobrazbo s področja drugih tehničnih ved ter kar 87,5 \% projektnih vodij z netehniško izobrazbo. Metodo interne donosnosti uporablja $60 \%$ projektnih vodij z izobrazbo s področja drugih tehniških ved in 81,3 \% projektnih vodij z netehniško izobrazbo.

Naglo razširitev uporabe metod, ki temeljijo na diskontiranju denarnega toka, gre gotovo pripisati razvoju računalnikov in programske opreme, saj funkcije za izračun neto sedanje vrednosti in interne donosnosti spadajo v standardni nabor boljših finančnih kalkulatorjev in elektronskih preglednic. Posledica splošne razširjenosti teh metod pa je tudi pomanjkljivo poznavanje njihovih specifičnih značilnosti. Raziskave so pokazale, da po lastnem mnenju le 50 \% slovenskih projektnih vodij z izobrazbo s področja gradbeništva pozna navzkrižno indikacijo (angl. conflict indication) metod neto sedanje vrednosti in interne donosnosti, enak delež pa pri isti metodi pozna večkratno (multiplo) notranjo stopnjo donosnosti. Pri tem je treba poudariti, da projektni vodje z izobrazbo s področja drugih tehniških ved še slabše poznajo posebnosti 
omenjenih metod $(29,4$ \% jih pozna navzkrižno indikacijo obeh metod in 35,3 \% jih pozna večkratno notranjo stopnjo donosa). Enako velja za projektne vodje z netehniško izobrazbo, pri čemer jih le 43,8 \% pozna navzkrižno indikacijo obeh metod in 18,8 \% večkratno notranjo stopnjo donosnosti (Pšunder in Ferlan, 2008).

Splošna razširjenost metod, ki temeljijo na diskontiranju denarnega toka, pa ni omejena zgolj na analizo nepremičninskih naložb, temveč se uporablja tudi za presojo naložb in naložbenih projektov na drugih področjih, od presojanja upravičenosti nabave novih strojev oziroma opreme v strojništvu pa vse do ocenjevanja vrednosti podjetij in drugih naložb, ki ustvarjajo denarni tok. Poleg tega na zasnovi večobdobnega obravnavanja vrednosti nepremičnin temelji ocenjevanje vrednosti posebnih nepremičnin v sistemu množičnega vrednotenja. Urad za množično vrednotenje nepremičnin pri vrednotenju posebnih nepremičnin uporablja metodo neposredne kapitalizacije in metodo diskontiranega denarnega toka (Suhadolc, 2009). Obe metodi sta v tesni povezavi z metodo neto sedanje vrednosti, kar pomeni, da tudi zanju smiselno veljajo ugotovitve o pomenu uporabe ustrezne diskontne mere iz tega prispevka.

Zlasti v zadnjih desetletjih postajajo metode, ki temeljijo na diskontiranju denarnega toka, vse bolj razširjene tudi zaradi uveljavljanja koncepta upoštevanja stroškov v celotni življenjski dobi projekta (angl. life cycle cost analysis - LCCA). LCCA je namreč metoda za ocenjevanje vseh stroškov, povezanih z lastništvom nekega projekta (na primer zgradbe), torej se pri njej upoštevajo vsi stroški, povezani s pridobitvijo projekta, lastništvom in odstranitvijo v njegovi življenjski dobi (Fuller, 2009).

\section{SEDANJA VREDNOST PRIHODNJIH DENARNIH TOKOV}

Metode na podlagi diskontiranja denarnega toka temeljijo na preračunavanju prihodnjih denarnih zneskov na čas začetka naložbe. Pri metodi neto sedanje vrednosti tako izenačimo začetno naložbo in sedanjo vrednost prihodnjih denarnih tokov, ki so posledica te naložbe. Datum začetne naložbe je točka, na katero preračunavamo prihodnje denarne tokove, zato začetne naložbe ne diskontiramo, seveda pa ima - ker je po vsebini denarni odtok - negativni predznak. Prihodnje

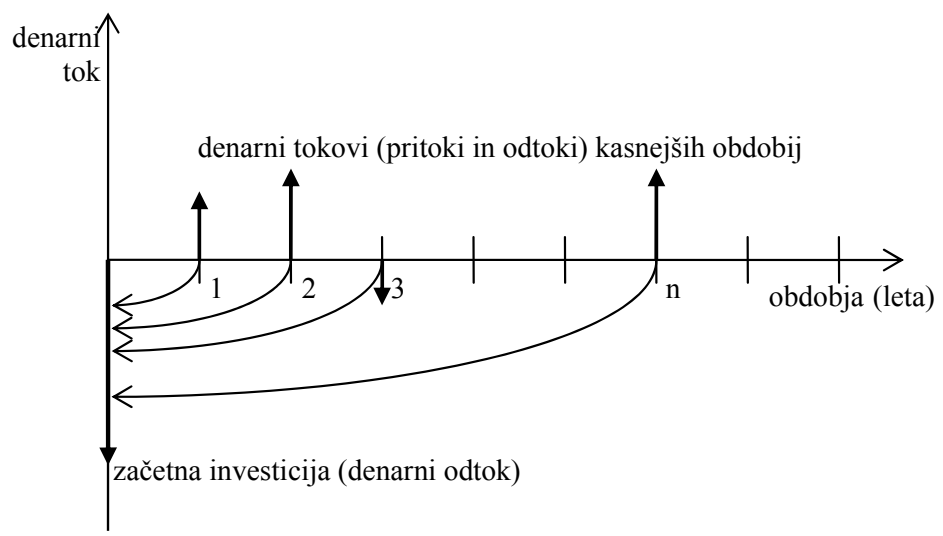

Prikaz 1: Diskontiranje denarnih tokov poznejših obdobij na datum začetne naložbe 
denarne tokove preračunavamo na dan naložbe. Ker pričakujemo, da bodo to denarni pritoki, jim praviloma dodelimo pozitiven predznak, mogoče pa so tudi izjeme, na primer pri velikih naložbah v obnove zgradb ali njihovih delov, za katere izračunavamo neto sedanjo vrednost. Zapisano je ponazorjeno v prikazu 1.

Ling in Archer (2008) poudarjata, da je treba poleg denarnih tokov iz naložbe upoštevati tudi denarni tok od prodaje premoženja. $V$ takšnih primerih je treba $v$ zadnji denarni tok vključiti tudi morebitno preostalo (prodajno) vrednost naložbe. Ta se običajno pojavi kot pozitiven denarni tok, včasih pa tudi kot negativen, na primer pri odstranitvi premoženja trajne odpadne ali tako majhne vrednosti, da so denarni odtoki zaradi odstranitve večji kot pritoki od likvidiranega premoženja.

Če prikazano zapišemo v obliki enačbe, dobimo:

$$
N P V=-I_{0}+P V \text {, }
$$

kjer $N P V$ pomeni neto sedanjo vrednost, $I_{0}$ začetno naložbo in $P V$ sedanjo vrednost prihodnjih denarnih tokov. Sedanjo vrednost prihodnjih denarnih tokov lahko povzamemo po Damodaranu (1996), pri čemer dobi enačba za izračun neto sedanje vrednosti naslednjo obliko:

$$
N P V=-I_{0}+\sum_{i=1}^{n} \frac{C F_{i}}{(1+r)^{i}},
$$

kjer je $C F_{i}$ denarni tok i-tega obdobja, $n$ število obdobij in $r$ diskontna mera.

\subsection{Pomen diskontne mere}

Ključen element za preračunavanje prihodnjih denarnih tokov na sedanjo vrednost je diskontna mera. Če bi bila 0 , bi se enačba 2 zreducirala zgolj na seštevanje in odštevanje denarnih tokov različnih časovnih obdobij, brez upoštevanja časovne razsežnosti denarja. Diskontna mera določa "ceno denarja« (natančneje, zahtevano donosnost), ki jo vlagatelj zahteva za neko naložbo, in bistveno vpliva na neto sedanjo vrednost. Zaradi višje diskontne mere se neto sedanja vrednost zmanjša, zaradi nižje pa se poviša, kar je razvidno iz prikaza 2.

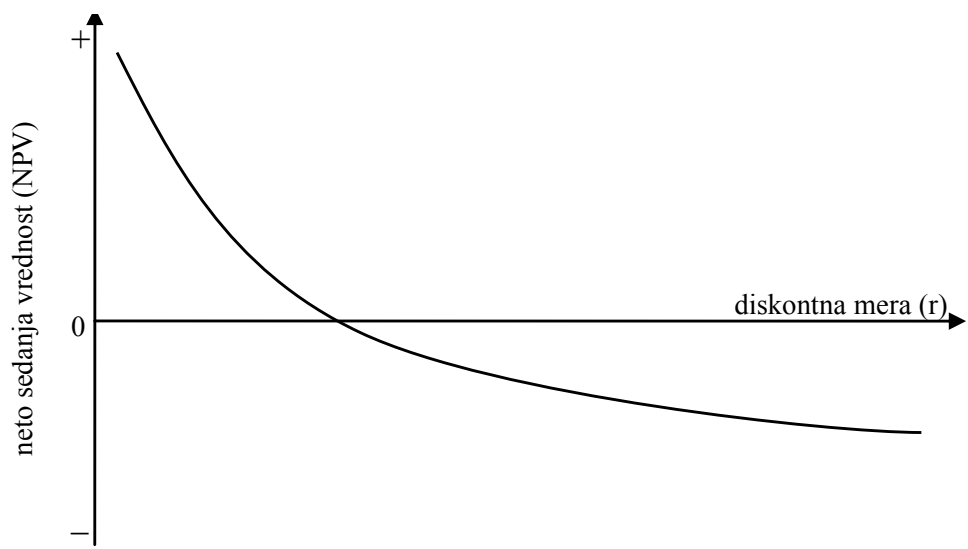

Prikaz 2: Vpliv diskontne mere na neto sedanjo vrednost 
$\mathrm{Z}$ višanjem diskontne mere neto sedanja vrednost naložbe pada. Ko doseže vrednost 0 , rečemo, da je diskontna mera enaka notranji stopnji donosnosti naložbe (angl. internal rate of return IRR). V tem primeru ima enačba obliko:

$$
0=-I_{0}+\sum_{i=1}^{n} \frac{C F_{i}}{(1+I R R)^{i}} .
$$

Znaki, uporabljeni v enačbi 3, so pojasnjeni zgoraj.

Notranjo stopnjo donosnosti je sicer teže izračunati kot neto sedanjo vrednost, kljub pomanjkljivostim pa se pogosto uporablja, saj je izračunana vrednost bolj razumljiva kot rezultat pri neto sedanji vrednosti.

\subsection{Sestava diskontne mere}

Diskontna mera oziroma diskontna stopnja (angl. discount rate) je količina, s katero pretvarjamo prihodnje denarne zneske $\mathrm{v}$ sedanjo vrednost. Uporabljena diskontna mera odseva celoten zahtevan donos na naložbo (tekoči in kapitalski del donosnosti), v odvisnosti od stopnje tveganja, povezanega s konkretno naložbo (Riggs, 1996). Pogosta praksa pri analizi nepremičninskih naložb je izkustvena določitev diskontne mere ali določitev diskontne mere na podlagi referenčnih podatkov. Tako denimo Cetl, Rioć in Mastelić Ivić (2008) kot diskontno mero pri projektu izboljšanja infrastrukture prostorskih podatkov privzamejo obrestno mero centralne banke, Kunič in Krainer (2010) pa za določanje ekonomične debeline toplotnoizolacijskih slojev v ravnih stenah privzemata ocenjeno diskontno mero $5 \%$. V primerjavi z navedenimi diskontnimi merami se za naložbe na področju javnih financ uporablja splošna diskontna mera 7 \% (Uredba o enotni metodologiji za pripravo in obravnavo naložbene dokumentacije na področju javnih financ, 2006). Navedene razlike med uporabljenimi diskontnimi merami bi tudi pri istih naložbah privedle do bistveno različnih rezultatov. V empiričnem delu članka prikazujemo, kako odločilen je lahko vpliv določitve ustrezne diskontne mere.

Sodobna teorija določanja diskontne mere napeljuje na višjo raven določenosti diskontne mere, predvsem v odvisnosti od tveganja. Kadar imamo opraviti s sredstvi, ki se slabšajo (amortizirajo), moramo diskontni meri prišteti še premijo za ohranitev kapitala. Tako dobimo mero kapitalizacije. Friedman in Ordway (1989) pišeta, da je "v ocenjevanju vrednosti nepremičnin in naložbenem izrazoslovju mera kapitalizacije opredeljena kot skupek donosa na kapital in ohranitve kapitala, medtem ko je v finančnem in ekonomskem izrazoslovju mera kapitalizacije opredeljena le kot donos naložbe«. Diskontna mera torej ne vsebuje premije za ohranitev kapitala in jo lahko uporabimo le, kadar ne pričakujemo sprememb v vrednosti naložbe ali pa lahko pričakujemo, da bodo spremembe vrednosti naložbe zajete pri prodaji premoženja ali ob zaključku naložbe (prirejeno po Friedman in Ordway, 1989, in The Appraisal of Real Estate, 1996). Velja torej, da je treba v primerih, ko imamo opraviti s sredstvi, ki se slabšajo, in slabšanja ne moremo izraziti v enačbi (na primer pri ocenjevanju vrednosti nepremičnin po načinu kapitalizacije donosa ali pri presoji naložb, ki temeljijo na predpostavki trajnega poslovanja (angl. goin concern)), v meri kapitalizacije zajeti poslabšanje sredstev. 
Naštete količine bi lahko razdelili v tri kategorije: donosnost netveganih naložb, pribitke za tveganja pri naložbi in - pri naložbah, ki so podvržene amortizaciji in tega ne izrazimo v spremenjenih denarnih tokovih (npr. ob prodaji premoženja) - v premijo za nadomestitev zmanjšanja vrednosti vložka, ki ji pogosteje rečemo premija za ohranitev kapitala ali glavnice. Zapisano ponazarjamo v prikazu 3.

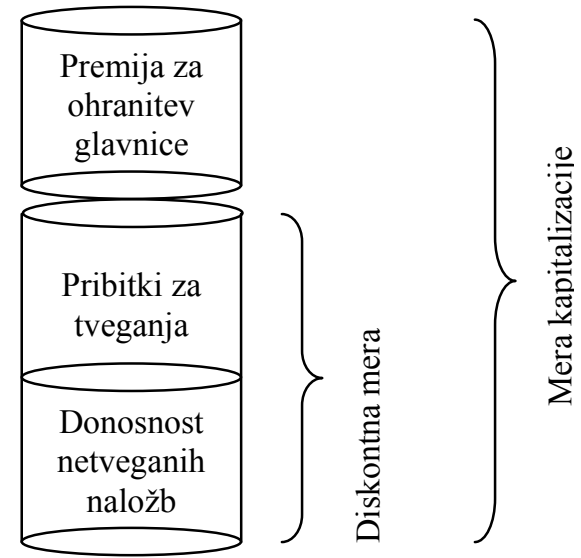

Prikaz 3: Sestava mere kapitalizacije: diskontna mera in premija za ohranitev glavnice

Diskontna mera temelji na donosnosti, ki jo je na finančnem trgu mogoče dobiti za podobno naložbo s primerljivim tveganjem. Kolikšno donosnost bomo za neko naložbo dejansko zahtevali, je odvisno od njenega tveganja in donosnosti po tveganju primerljivih naložb (Mramor, 1993). Bruggeman in Fisher (2002) ta odnos med tveganjem in donosnostjo pri različnih naložbah opišeta z naslednjim prikazom (prikaz 4):

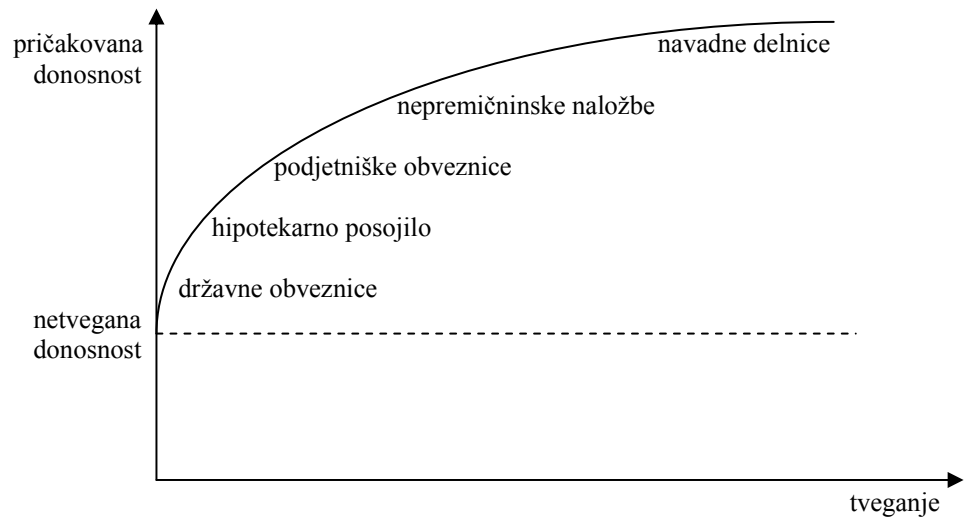

Prikaz 4: Odnos med tveganjem in pričakovano donosnostjo različnih vrst naložb (Bruggeman in Fischer, 2002)

Pribitek za tveganja (v katerega vključujemo tudi pribitek za manjšo likvidnosti in gospodarjenje z naložbo) lahko opustimo le, če izvajamo naložbo v netvegane vrednostne papirje, na področju nepremičninskih naložb pa netveganih naložb ni mogoče najti. Pri različnih nepremičninskih 
projektih lahko upoštevamo različna tveganja, kar nam omogoča, da primerjamo tudi dva različno tvegana projekta.

Naložbe v nepremičnine so večinoma podvržene poslabšanju in zastaranju, zaradi česar lahko naložba na daljši rok izgublja vrednost. Izgubo vrednosti lahko sicer upoštevamo pri denarnem toku iz preostale vrednosti (zadnjem denarnem toku, kadar nam zasnova uporabljene enačbe to omogoča; na primer metoda neto sedanje vrednosti pri analizi nepremičninskih naložb). Če pa tega ne moremo zajeti v uporabljeni enačbi (na primer pri metodi neposredne kapitalizacije za ocenjevanje vrednosti nepremičnin), moramo zmanjšanje vrednosti sredstva zajeti z izračunom premije za ohranitev glavnice.

Netvegano donosnost za gradbene projekte privzamemo iz donosnosti do zapadlosti pri državnih obveznicah z ročnostjo, ki je podobna ročnosti projekta. Donosnost državnih obveznic lahko pridobimo iz javnih spletnih portalov (na primer MTS Slovenia Daily Fixing, 2010), izračunavajo pa jo tudi naložbeni oddelki finančnih ustanov. Pribitek za tveganja se v praksi marsikdaj določa izkustveno ali z opiranjem na teoretične vire.

Premija za ohranitev glavnice, ki se uporablja pri meri kapitalizacije, se izračunava po treh metodah: Ringovi (časovno enakomerni metodi), Hoskoldovi (metodi amortizacijskega sklada) in Inwoodovi (anuitetni metodi). Čeprav je za potrebe ocenjevanja vrednosti nepremičnin uporabo slednjih dveh na splošno laže utemeljiti, uporaba Ringove oziroma časovno enakomerne metode določitve premije za ohranitev glavnice ne bo bistveno vplivala na rezultat.

Diskontno mero je sicer mogoče določiti tudi z zahtevnejšimi znanstveno utemeljenimi metodami, med katere spadajo model določanja cen dolgoročnih naložb (angl. capital asset pricing model CAPM), model enakomerne rasti dividend (angl. dividend growth model) in metoda na podlagi teorije cenovne arbitraže (angl. arbitrage pricing theory) (Brigham in Gapenski, 1996).

Diskontna mera izjemno močno vpliva na rezultat metode neto sedanje vrednosti, zato je njeno pravilno določanje pogoj za pravilnost analize.

\section{ANALIZA VPLIVA DISKONTNIH MER: PRIMER NETO SEDANJE VREDNOSTI}

Analizo vplivnosti diskontnih mer izvedemo na podlagi metode neto sedanje vrednosti. Ker metoda temelji na izenačevanju začetne naložbe in sedanje vrednosti prihodnjih denarnih tokov, pri čemer je začetna naložba znana, so rezultati analize tudi smiselno prenosljivi na metode vrednotenja nepremičnin, tudi na tiste, ki bodo uporabljene za ocenjevanje vrednosti posebnih nepremičnin v sistemu množičnega vrednotenja nepremičnin v Sloveniji (glej Suhadolc, 2009).

Pri izvedbi simulacije vplivnosti diskontne mere predpostavimo, da imamo opraviti s stalnimi letnimi denarnimi tokovi nekega projekta $(C F)$. Ob tej predpostavki lahko enačbo 2 zapišemo tako, da iz desnega člena izpostavimo spremenljivko $C F$, kar izrazimo z enačbo:

$$
N P V=-I_{0}+C F \cdot \sum_{i=1}^{n} \frac{1}{(1+r)^{i}} \cdot
$$


Spremenljivke so pojasnjene med besedilom.

$\mathrm{V}$ desnem členu enačbe prepoznamo geometrijsko zaporedje $\sum_{i=1}^{n} \frac{1}{(1+r)^{i}}$, katerega vsoto pri $n$ številu členov lahko zapišemo tudi kot faktor sedanje vrednosti prihodnjih anuitet (angl. present value of invested future annuities) $\frac{(1+r)^{n}-1}{(1+r)^{n} \cdot r}$ (prirejeno po Baum, Mackmin in Nunnington, 1998). Enačbo 4 lahko tako zapišemo tudi z uporabo faktorja sedanje vrednosti:

$$
N P V=-I_{0}+C F \cdot \frac{(1+r)^{n}-1}{(1+r)^{n} \cdot r} .
$$

Za slikovitejšo razpravo označimo faktor sedanje vrednosti s PVIFA (iz angleščine: present value of invested future annuities). Sedaj dobi enačba 5 obliko

$$
N P V=-I_{0}+C F \cdot P V I F A \text {. }
$$

Faktor sedanje vrednosti je odvisen od trajanja in seveda od uporabljene diskontne mere. Na podlagi enačb 5 oziroma 6 bomo v empiričnem delu pokazali vpliv diskontne mere na rezultate presoje naložb in tudi ocenjevanja vrednosti nepremičnin.

\subsection{Vpliv diskontne mere na faktor sedanje vrednosti}

Kadar analiziramo neki projekt, so višina začetne naložbe, pričakovani denarni tokovi in predvideno trajanje projekta znani. Ključna spremenljivka, ki še vpliva na rezultat analize (ali vrednotenja, če je zasnova izračuna takšna), je diskontna mera. Od nje je odvisno, ali so projekti pri isti naložbi, istih predvidenih denarnih tokovih ali istem trajanju ocenjeni kot uspešni ali ne. Vpliv uporabljene diskontne mere pa bistveno narašča s trajanjem projekta. Vpliv diskontne mere na faktor sedanje vrednosti prihodnjih anuitet $\mathrm{v}$ odvisnosti od trajanja projekta je prikazan v prikazu 5.

Iz prikaza je razvidno, da ima razlika $v$ diskontni meri večji vpliv na projekte $\mathrm{z}$ daljšim trajanjem ter da so razlike večje pri nižjih diskontnih merah. Če vzamemo za primer naložbo z amortizacijsko dobo 20 let (krajše so pri nepremičninskih naložbah in v gradbeništvu redkost) in trajanje naložbe prilagodimo amortizacijski dobi, lahko ugotovimo, da znaša faktor sedanje vrednosti pri 3-odstotni diskontni meri 14,88, kar je za več kot 50 \% več kot pri 9-odstotni diskontni meri, pri kateri znaša faktor sedanje vrednosti 9,13, in dvakrat več, kot znaša faktor sedanje vrednosti pri 13-odstotni diskontni meri. To tudi pomeni, da v intervalu diskontnih od $3 \%$ do $13 \%$ pri ocenitvi sedanje vrednosti denarnih tokov naredimo napako za faktor 2, kar seveda lahko pomeni tudi napačno indikacijo (odločitev) analize. Natančne vrednosti faktorjev sedanje vrednosti prihodnjih anuitet v odvisnosti od diskontnih mer na intervalu od $3 \%$ do $15 \%$ ter za izbrana trajanja naložb so navedene v preglednici 1 . 


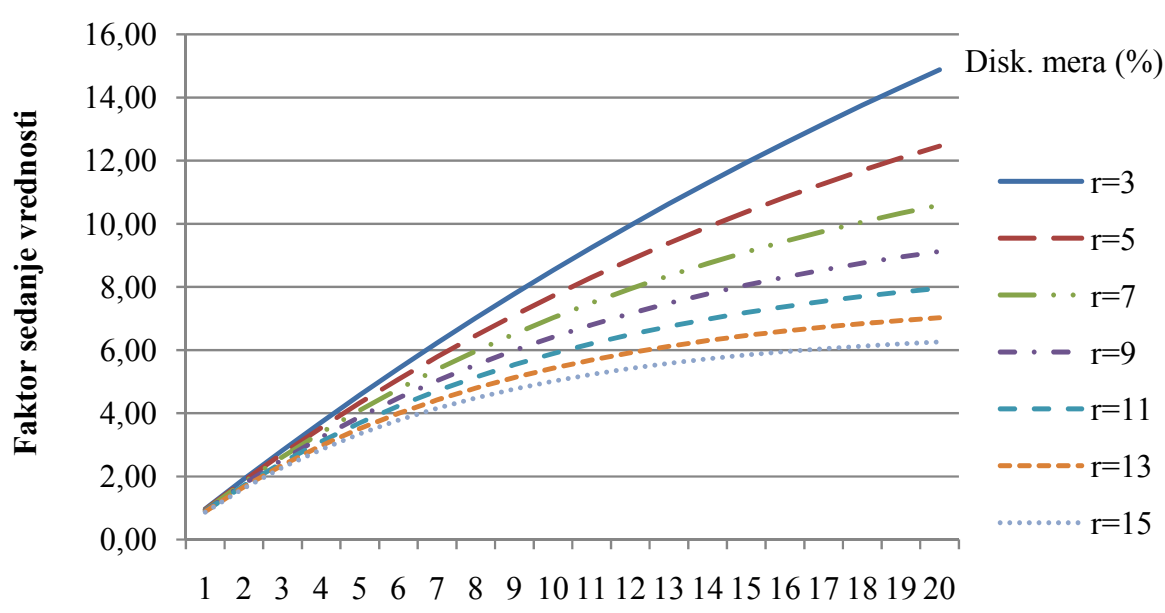

Trajanje projekta (leta)

Prikaz 5: Faktor sedanje vrednost prihodnjih anuitet v odvisnosti od diskontne mere (r) in trajanja projekta ( $n$ )

\begin{tabular}{lccccccc}
\hline Diskontna & \multicolumn{7}{c}{ Trajanje projekta (leta) } \\
\cline { 2 - 7 } mera (r) & 1 & 3 & 5 & 7 & 10 & 15 & 20 \\
\hline 3 & 0,97 & 2,83 & 4,58 & 6,23 & 8,53 & 11,94 & 14,88 \\
4 & 0,96 & 2,78 & 4,45 & 6,00 & 8,11 & 11,12 & 13,59 \\
5 & 0,95 & 2,72 & 4,33 & 5,79 & 7,72 & 10,38 & 12,46 \\
6 & 0,94 & 2,67 & 4,21 & 5,58 & 7,36 & 9,71 & 11,47 \\
7 & 0,93 & 2,62 & 4,10 & 5,39 & 7,02 & 9,11 & 10,59 \\
8 & 0,93 & 2,58 & 3,99 & 5,21 & 6,71 & 8,56 & 9,82 \\
9 & 0,92 & 2,53 & 3,89 & 5,03 & 6,42 & 8,06 & 9,13 \\
10 & 0,91 & 2,49 & 3,79 & 4,87 & 6,14 & 7,61 & 8,51 \\
11 & 0,90 & 2,44 & 3,70 & 4,71 & 5,89 & 7,19 & 7,96 \\
12 & 0,89 & 2,40 & 3,60 & 4,56 & 5,65 & 6,81 & 7,47 \\
13 & 0,88 & 2,36 & 3,52 & 4,42 & 5,43 & 6,46 & 7,02 \\
14 & 0,88 & 2,32 & 3,43 & 4,29 & 5,22 & 6,14 & 6,62 \\
15 & 0,87 & 2,28 & 3,35 & 4,16 & 5,02 & 5,85 & 6,26 \\
\hline
\end{tabular}

Preglednica 1: Faktor sedanje vrednosti serije stalnih denarnih tokov (prihodnjih anuitet) v odvisnosti od diskontne mere in trajanja naložbe 


\subsection{Potrebna letna višina stanovitnih denarnih tokov, da je naložba upravičena}

Naložba je upravičena, ko je NPV enak ali večji od 0. Tako mora za izbrani primer 20-letne naložbe stanovitni prihodnji denarni tok pri diskontni meri $3 \%$ na letni ravni dosegati zgolj 6,7 \% začetne naložbe, da bi z analizo dobili pozitivno indikacijo, pri diskontni meri $15 \%$ pa mora za pozitivno indikacijo znašati več kot dvakrat več. Ugotovimo lahko tudi, da je 20-letna naložba, pri istem začetnem vložku in istih stanovitnih letnih denarnih tokovih (konkretno 7,4 \% naložbe) pri uporabljeni 4-odstotni diskontni meri upravičena, pri uporabljeni 5-odstotni diskontni meri pa ne. Letne denarne tokove, ki so potrebni za upravičenosti naložbe, izražene v deležu začetnega vložka in v odvisnosti od trajanja naložbe ter uporabljene diskontne mere, za izbrana trajanja projekta in diskontne mere na intervalu od $3 \%$ do $15 \%$ podajmo v preglednici 3 .

\begin{tabular}{lccccccc}
\hline Diskontna & \multicolumn{7}{c}{ Trajanje projekta (leta) } \\
\cline { 2 - 7 } mera (r) & 1 & 3 & 5 & 7 & 10 & 15 & 20 \\
\hline 3 & 1,030 & 0,354 & 0,218 & 0,161 & 0,117 & 0,084 & 0,067 \\
4 & 1,040 & 0,360 & 0,225 & 0,167 & 0,123 & 0,090 & 0,074 \\
5 & 1,050 & 0,367 & 0,231 & 0,173 & 0,130 & 0,096 & 0,080 \\
6 & 1,060 & 0,374 & 0,237 & 0,179 & 0,136 & 0,103 & 0,087 \\
7 & 1,070 & 0,381 & 0,244 & 0,186 & 0,142 & 0,110 & 0,094 \\
8 & 1,080 & 0,388 & 0,250 & 0,192 & 0,149 & 0,117 & 0,102 \\
9 & 1,090 & 0,395 & 0,257 & 0,199 & 0,156 & 0,124 & 0,110 \\
10 & 1,100 & 0,402 & 0,264 & 0,205 & 0,163 & 0,131 & 0,117 \\
11 & 1,110 & 0,409 & 0,271 & 0,212 & 0,170 & 0,139 & 0,126 \\
12 & 1,120 & 0,416 & 0,277 & 0,219 & 0,177 & 0,147 & 0,134 \\
13 & 1,130 & 0,424 & 0,284 & 0,226 & 0,184 & 0,155 & 0,142 \\
14 & 1,140 & 0,431 & 0,291 & 0,233 & 0,192 & 0,163 & 0,151 \\
15 & 1,150 & 0,438 & 0,298 & 0,240 & 0,199 & 0,171 & 0,160 \\
\hline
\end{tabular}

Preglednica 2: Stanovitni letni denarni tokovi, potrebni za pozitivno indikacijo analize neto sedanje vrednosti, izraženi v deležu začetnega vložka.

\section{RAZISKAVA UPORABE DISKONTNE MERE IN MERE KAPITALIZACIJE MED POOBLAŠČENIMI OCENJEVALCI VREDNOSTI NEPREMIČNIN}

\subsection{Raziskovalni okvir}

Glede na izrazito različnost uporabljanih diskontnim mer in mer kapitalizacije, ki jih je mogoče opaziti s primerjanjem različnih javno dostopnih objav, smo se odločili izvesti raziskavo o uporabi diskontne mere in mere kapitalizacije med strokovnjaki v Sloveniji. Namen raziskave 
je bil ugotoviti, kakšna je višina diskontne mere oziroma mere kapitalizacije, ki jo uporabljajo pri vrednotenju izbranih tipov nepremičnin oziroma presoji izbranih tipov nepremičninskih naložb. Obenem smo povpraševali po uporabni realne in nominalne netvegane donosnosti. Cilj raziskave je bil izdelati statistično utemeljen in sistematiziran pregled uporabe diskontne mere in mere kapitalizacije v odnosu do donosnosti netveganih naložb ter na podlagi statističnih obdelav sklepati o premijah za tveganja ter premijah za ohranitev glavnice pri posameznih tipih naložb.

\subsection{Vzorec in zbiranje podatkov}

Podatke smo zbirali z metodo anketiranja. Anketa je bila pripravljena v obliki spletne strani, povabljenim izpolnjevalcem pa smo jo posredovali tudi v obliki besedilne datoteke. Vzorec anketirancev je obsegal vse pooblaščene ocenjevalce vrednosti nepremičnin, ki so bili ob anketiranju vpisani register pooblaščenih ocenjevalcev vrednosti nepremičnin (70 povabljenih anketirancev). Anketa se je izvajala v drugi polovici februarju in začetku marca 2011. Odziv anketirancev je bil 32,9-odstoten, kar pomeni, da analiza vsebuje odgovore skoraj tretjine vseh pooblaščenih ocenjevalcev vrednosti nepremičnin v Sloveniji, na podlagi česar menimo, da so rezultati analize referenčni.

Vprašalnik je bil sestavljen iz treh sklopov. V prvem delu smo povpraševali po realni in nominalni donosnosti netveganih naložb v februarju 2011 ter njuni uporabi. Na podlagi omenjenih podatkov je mogoče izračunati, kakšna je pričakovana dolgoročna letna inflacija, ki jo anketiranci upoštevajo pri svojih ocenah. Drugi sklop vprašanj se je nanašal na uporabljano diskontno mero pri naslednjih tipih nepremičnin: zemljišča, stanovanja, stanovanjske hiše, poslovni prostori, trgovski prostori in industrijske nepremičnine, ter pri naslednjih tipih nepremičninskih naložb: naložbe v izboljšave (dograditve ipd.), graditve za znanega kupca in graditve za trg. Pri nepremičninah smo dodatno povpraševali po razliki med uporabljeno diskontno mero na boljših in slabših lokacijah. Namen te delitve je bil pridobiti podatek o razliki med pričakovano dolgoročno rastjo vrednosti nepremičnin, ki jo anketiranci pričakujejo v prihodnosti. Tretji sklop vprašanj se je nanašal na uporabljeno mero kapitalizacije pri enakih tipih nepremičnin oziroma nepremičninskih naložb kot pri drugem sklopu vprašanj. Namen tega vprašanja je bil pridobiti podatek o premiji za ohranitev glavnice, ki jo anketiranci upoštevajo pri ocenjevanju vrednosti posameznega tipa nepremičnine.

\subsection{Analiza podatkov}

Podatke smo sistematizirali in statistično analizirali s programskim paketom PASW Statistics. Izračunavali smo osnovne univariatne statistike (aritmetične sredine in standardni odklon) pri posameznih vprašanjih ter jih obdelali ločeno za anketirance, ki so odgovorili, da uporabljajo nominalne donosnosti, in za tiste, ki so odgovorili, da uporabljajo realne donosnosti. Na podlagi razlik med zahtevanimi stopnjami donosnosti in donosnostmi netveganih naložb smo izračunali tudi premije za tveganje in premije za ohranitev glavnice po posameznih tipih nepremičnin. 


\section{REZULTATI}

Anketirane pooblaščene ocenjevalce vrednosti nepremičnin smo uvodoma vprašali, ali pri svojih ocenah uporabljajo pretežno nominalno ali realno donosnost. Le 28,6 \% jih je odgovorilo, da pri ocenitvah vrednosti in naložbenih analizah pretežno uporablja nominalno donosnost, kar je skladno s pričakovanji in teoretičnimi izhodišči. Velika večina ocenitev vrednosti nepremičnin in naložbenih analiz namreč temelji na stalnih cenah (ki jih z leti ne prilagajamo inflaciji), zato je smiselno tudi pri uporabljenih donosnostih skladno z načeli Fisherjeve enačbe nominalno donosnost preračunati na realno.

\begin{tabular}{lcc}
\hline Netvegana donosnost & Povprečje & Standardni odklon \\
\hline nominalna & 4,20 & 1,25 \\
realna & 1,91 & 0,74 \\
\hline pričakovana inflacija & 2,25 & \\
\hline
\end{tabular}

Preglednica 3: Nominalna in realna donosnost ter pričakovana inflacija, izračunana po Fisherjevi enačbi.

Povprečna nominalna netvegana donosnost, ki smo jo izračunali na podlagi odgovorov anketirancev, znaša 4,20 \%. Povprečje se ujema s februarskimi donosnostmi obveznic Republike

\begin{tabular}{|c|c|c|}
\hline \multirow[t]{2}{*}{ Premija za tveganja } & \multicolumn{2}{|c|}{ Standardni } \\
\hline & Povprečje & odklon \\
\hline zemljišča na boljših lokacijah & 3,61 & 2,79 \\
\hline zemljišča na slabših lokacijah & 3,93 & 2,58 \\
\hline stanovanja na boljših lokacijah & 3,60 & 1,98 \\
\hline stanovanja na slabših lokacijah & 4,15 & 2,10 \\
\hline stanovanjske hiše na boljših lokacijah & 4,14 & 2,13 \\
\hline stanovanjske hiše na slabših lokacijah & 4,69 & 2,37 \\
\hline poslovni prostori na boljših lokacijah & 4,71 & 1,90 \\
\hline poslovni prostori na slabših lokacijah & 5,30 & 2,32 \\
\hline trgovski prostori na boljših lokacijah & 5,04 & 2,16 \\
\hline trgovski prostori na slabših lokacijah & 5,79 & 2,60 \\
\hline industrijske nepremičnine & 5,98 & 2,86 \\
\hline naložbe v izboljšave (dograditve ipd.) & 4,91 & 3,07 \\
\hline graditve za znanega kupca & 5,42 & 2,46 \\
\hline graditve za trg & 5,95 & 3,30 \\
\hline
\end{tabular}

Preglednica 4: Premije za tveganja za različne vrste nepremičnin (razlika med diskontno mero in netvegano donosnostjo) 
Slovenije, ki zapadajo v obdobju od 7 do 8 let (na primer SI0002102794). Iz podatka o realni donosnosti, katere povprečje je izračunano na $1,91 \%$, je mogoče izračunati, da anketiranci pričakujejo v prihodnosti inflacijo v višini 2,25, iz česar je mogoče sklepati, da anketiranci v Sloveniji pričakujejo nekoliko višjo inflacijo, kot je ciljna inflacija Evropske centralne banke $(2,00 \%)$. Univariatne statistike netveganih donosnosti prikazujemo v preglednici 3.

Na podlagi razlik med diskontnimi merami in donosnostmi netveganih naložb smo izračunali premije za tveganja (vključno s premijo za manjšo likvidnost in premijo za gospodarjenje $\mathrm{z}$ naložbo), ki jih povzemamo v preglednici 4.

Opazimo lahko, da premija za tveganja (vključno s premijo za manjšo likvidnost in premijo za gospodarjenje z naložbo) narašča skladno s teoretičnimi pričakovanji. Kot je mogoče ugotoviti iz rezultatov, anketiranci menijo, da so zemljišča najmanj tvegana oblika nepremičnin, sledijo stanovanja, stanovanjske hiše, poslovni prostori, trgovski prostori in na koncu industrijske nepremičnine. Iz odgovorov je mogoče ugotoviti, da veljajo nepremičnine določenega tipa za manj tvegane, še posebej, če so na boljših lokacijah. Analiza odgovorov glede nepremičninskih naložb pokaže, da anketiranci ocenjujejo premijo za tveganja med 4,91 \% za izboljšave oziroma dograditve in $5,95 \%$ za graditve za trg.

$\mathrm{Na}$ podlagi razlik med mero kapitalizacije in diskontno mero smo izračunali tudi premijo za ohranitev kapitala, ki jo za posamezne tipe nepremičnin navajamo v preglednici 5.

\begin{tabular}{lcc}
\hline & & Standardni \\
Premija za ohranitev kapitala & Povprečje & odklon \\
\hline zemljišča na boljših lokacijah & 0,45 & 0,98 \\
zemljišča na slabših lokacijah & 0,40 & 1,04 \\
stanovanja na boljših lokacijah & 1,09 & 0,86 \\
stanovanja na slabših lokacijah & 1,20 & 0,84 \\
stanovanjske hiše na boljših lokacijah & 1,06 & 0,89 \\
stanovanjske hiše na slabših lokacijah & 1,08 & 0,75 \\
poslovni prostori na boljših lokacijah & 0,98 & 0,79 \\
poslovni prostori na slabših lokacijah & 1,12 & 0,80 \\
trgovski prostori na boljših lokacijah & 1,11 & 0,98 \\
trgovski prostori na slabših lokacijah & 1,12 & 1,01 \\
industrijske nepremičnine & 1,24 & 0,87 \\
naložbe v izboljšave (dograditve ipd.) & 1,05 & 1,34 \\
graditve za znanega kupca & 0,93 & 1,06 \\
graditve za trg & 0,84 & 1,00 \\
\hline
\end{tabular}

Preglednica 5: Premija za ohranitev kapitala (razlika med mero kapitalizacije in diskontno mero) 
Ugotovimo lahko, da se premija za ohranitev kapitala pri vseh tipih nepremičnin, z izjemo zemljišč, giblje med $0,84 \%$ in 1,24 \%. Zanimiva je ugotovitev, da so bile nekatere izračunane premije za ohranitev kapitala celo negativne. Teoretično je to sicer sprejemljivo, vendar le, če je obseg slabšanja nepremičnin zaradi fizične obrabe ter funkcionalne in ekonomske zastarelosti manjši, kot pa znaša rast vrednosti nepremičnin. Sklepati je torej mogoče, da del anketirancev pričakuje ponovno rast nepremičninskega trga.

Pri zemljiščih je premija za ohranitev kapitala sicer nižja, vendar vseeno pozitivna. Ker se zemljišča ne slabšajo, je v nasprotju s pričakovanji mogoče sklepati, da anketiranci pričakujejo dolgoročno realno padanje vrednosti stavbnih zemljišč za 0,45 \% letno na boljših lokacijah oziroma za 0,40 \% letno na slabših. Pri naložbah v izboljšave (dograditvah) anketiranci ocenjujejo, da znaša premija za ohranite kapitala 1,05 \%, iz česar lahko sklepamo, da ocenjujejo, da se dograditve in druge izboljšave v povprečju slabšajo približno enako kot zgradbe, na katerih so bile izvedene.

\section{RAZPRAVA IN SKLEP}

Ugotovimo lahko, da sta diskontna mera oziroma mera kapitalizacije ključni spremenljivki analize naložb, enaka ugotovitev smiselno velja tudi za vrednotenje nepremičnin po metodah, ki temeljijo na diskontiranju denarnega toka. Za njuno določanje so sicer potrebne izkušnje, pa vendar ga ne smemo prepuščati zgolj izkustvenim postopkom ali celo okvirnim ocenam. Pri določitvi diskontne mere oziroma mere kapitalizacije moramo uporabiti znanstveno in strokovno potrjene metode, katerih zasnovo in način uporabe prikazujemo v tem delu. Le tako lahko pričakujemo, da bodo rezultati analiz in vrednotenj z metodami, ki temeljijo na diskontiranju denarnih tokov, zanesljivi in verodostojni.

Ključne ugotovitve raziskave o uporabi diskontne mere in mere kapitalizacije, ki smo jo izvedli med pooblaščenimi ocenjevalci vrednosti nepremičnin, so, da pooblaščeni ocenjevalci vrednosti nepremičnin pri delu pretežno uporabljajo realno donosnost državnih vrednostnih papirjev kot podlago za dograjevanje diskontne mere ali mere kapitalizacije. Povprečje, izračunano na podlagi odgovorov, sovpada s tržno donosnostjo državnih vrednostnih papirjev v času ankete. Iz primerjave nominalne in realne donosnosti je mogoče ugotoviti, da anketiranci pričakujejo dolgoročno v povprečju nekoliko višjo inflacijo, kot je ciljna inflacija Evropske centralne banke. Izračunana premija za tveganje je najnižja pri zemljiščih na boljših lokacijah, kjer znaša 3,61 \%, in najvišja za industrijske nepremičnine, kjer znaša 5,98 \%. Skladno s pričakovanji se premija za tveganja na slabših lokacijah nekoliko poveča za vse tipe nepremičnin.

Povprečna premija za ohranitev kapitala se pri različnih tipih nepremičnin giblje med 0,40 \% in $1,24 \%$. Tudi tukaj je najnižja za zemljišča in najvišja za industrijske nepremičnine ter nižja na boljših lokacijah kot na slabših. Izjema so zemljišča, pri katerih se premija za ohranitev kapitala med boljšimi in slabšimi lokacijami bistveno ne razlikuje.

Kljub splošni razširjenosti uporabe metod, ki temeljijo na diskontiranju denarnih tokov, je še vedno prisotno njihovo pomanjkljivo poznavanje in ponekod tudi napačna uporaba. Pravilnost metod temelji na pravilnosti uporabljenih vhodnih elementov - denarnih tokov, povezanih z 
naložbo, in predvsem na uporabljeni diskontni meri. Prav višina slednje je tista, ki lahko ključno spremeni odločitev, povezano z naložbo, saj že majhne spremembe v diskontni stopnji močno spremenijo odločitev o sprejetju ali zavrnitvi naložbe.

\section{Literatura in viri}

Baum, A., Mackmin, D., Nunnington, N. (1998). The Income Approach to Propety Valuation, 4. izdaja. Thomson Business Press.

Brigham, E. F., Gapenski, L. C. (1996). Intermediate Financial Management, 5. izdaja. The Dyrden Press.

Bruggeman, W. B., Fisher, J. D. (2002). Real Estate Finance and Investments - McGraw-Hill Irwin.

Cetl, V., Roić, M., Mastelić Ivić, S. (2008). Cost-Benefit Analysis of the Improvement of Spatial Data Infrastructure Case Study Croatia. Geodetski vestnik, 52(3), 475-486.

Damodaran, A. (1996). Investment Valuation. John Wiley \& Sons.

Friedman, J. P., Ordway, N. (1989). Income Property Appraisal and Analysis. American Society of Appraisers.

Fuller, S. (12. 7. 2009). Life-Cycle Cost Analysis (LCCA). National Institute of Standards and Technology (NIST).

Pridobljeno 23. 3. 2010 s spletne strani: http://www.wbdg.org/resources/lcca.php.

Klammer, T. P., Walker M. C. (1984). The continuing increase in the use of sophisticated capital budgeting techniques. California Management Review, 27(1), 137-148.

Kunič, $R$., Krainer, A. (2010). Ekonomična debelina slojev toplotnih izolacij v ravnih strehah/Economical Thickness of Thermal Insulation Layers in Flat Roofs. Gradbeni vestnik, januar, 2010(59), 6-12.

Ling, D. C., Archer, W. R. (2008). Real Estate Principles: A Value Approach, 2. izdaja. McGraw-Hill/Irwin.

Mramor, D. (1993). Uvod v poslovne finance, Gospodarski vestnik.

MTS Slovena Daily Fixing (2010). Dostopno: http://www.mtsdata.com/content/data/public/rsl/fixing/.

Pike, R. H. (1988). An empirical study of the adoption of sophisticated capital budgeting practices and decision making effectiveness. Accounting and Business Research, 18(72), 341-351.

Pšunder I. (2007). Ali dobro poznamo diskontno mero in mero kapitalizacije? V: Poslovanje z nepremičninami: 18. tradicionalno strokovno srečanje. Ljubljana: Inštitut za nepremičnine, 286-293.

Pšunder, I., Ferlan, N. (2008). Use of Capital Budgeting Methods for Investment Project Evaluation in the Field of Civil Engineering. American Journal of Applied Sciences, 5(1), 18-21.

Riggs, K. J. jr. (1996). Pricing risk: Choosing a discount rate, Real Estate Issues, 21(2), 16-22.

Suhadolc, M. (2009). Uporaba načina kapitalizacije donosa v sistemu množičnega vrednotenja posebnih nepremičnin. Geodetski vestnik, 53(3), 580-589.

The Appraisal of Real Estate, 12. izdaja (2001), Appraisal Institute.

Uredba o enotni metodologiji za pripravo in obravnavo naložbene dokumentacije na področju javnih financ(2006), Ur. I. RS, št. 60/2006.

Prispelo v objavo: 29. julij 2010

Sprejeto: 11. maj 2011

doc. dr. Igor Pšunder, univ. dipl. inž. grad.

Univerza v Mariboru

Fakulteta za gradbeništvo

E-pošta: igor.psunder@uni-mb.si

prof. dr. Andreja Cirman, univ. dipl. ekon.

Univerza v Ljubljani

Ekonomska fakulteta

E-pošta: andreja.cirman@ef.uni-lj.si 